\title{
TEACHING CHILDREN ABOUT NUTRITION: DEVELOPMENT OF THE VEGETABLE AND FRUIT EDUCATION ACTIVITY (VFEA)
}

\section{PhD. Wafaa Husain}

Home economics department, College of Basic Education, Kuwait

PhD. Sara D. Garduño-Diaz

Nutrition consultant at Your Choice Nutrition, Kuwait
By

PhD. Fatemah Ashkanani

Home economics department, College of Basic Education, Kuwait PhD. Santosh Khokhar School of Food Science and Nutrition, University of Leeds, UK

Research Gournal Specific Fducation

Faculty of Specific Education

gYansoura University

ISSUE NO. 38, APRIL. 2015

مجلة بحوث التربية النوعية - جامعة المنصورة

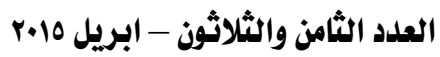


$=$ Teaching children about nutrition: development of the Vegetable and Fruit Education Activity $=$ 


\section{TEACHING CHILDREN ABOUT NUTRITION: DEVELOPMENT OF THE VEGETABLE AND FRUIT EDUCATION ACTIVITY (VFEA)}

PhD. Wafaa Husain *

PhD. Sara D. Garduño-Diaz ${ }^{* * *}$
PhD. Fatemah Ashkanani*

PhD. Santosh Khokhar ${ }^{* * * *}$

\section{Abstract}

Background: Public health campaigns are focused on promoting increased vegetable and fruit (VF) consumption due to their association with health. Although the number of suggested portions is generally known to children in the UK, knowledge of what counts and what doesn't count as a portion of these foods is not clear. We aimed to develop and test a succinct intervention about what constitutes a portion of VF.

Methods: A succinct (45min.) teaching intervention regarding VF portion sizes; including pre- and post evaluations though a structured questionnaire, demonstrations with real-life models and hands-on examination of portions, oral communications and active engagement in the form of entertainment, was carried out with boys and girls (7-9 years, $n=80)$ in various primary schools in Leeds. Activities included a question and answer session and individual and group competitions to confirm acquired knowledge.

Results: Initial knowledge was acceptable, with $85 \%$ of them being aware of the UK recommendations from the 5-a-day program. Knowledge of portion sizes was minimal with only $2 \%$ of the participants being able to correctly identify the corresponding portion sizes of apples, juice, grapes, peas and broccoli. The acquired knowledge from the teaching intervention was statistically significant $(\mathrm{p}=.000)$. Previous knowledge was higher among girls (86\% vs. $84 \%$ respectively) and acquired knowledge among

* Faculty of Home Economics, the Public Authority for Applied Education and Training, Kuwait

${ }^{* *}$ Nutrition consultant at Your Choice Nutrition, Kuwait

School of Food Science and Nutrition, University of Leeds, UK 
$=$ Teaching children about nutrition: development of the Vegetable and Fruit Education Activity $=$ boys (93\% vs. $88 \%$ respectively) although gender differences were not significant.

Conclusions: A succinct teaching intervention might be a feasible way to increase knowledge of VF portion sizes among primary school aged children.

\section{Introduction}

Vegetables and fruits are high in essential micronutrients (Newby, 2009) and dietary fibre (Anderson et al., 2009). Higher levels of VF intake may decrease the risk of cardiovascular disease, obesity and some cancers (IARC, 2003; Robertson et al., 2004). The World Health Organisation (WHO, 1990) has recommended a minimum daily intake of $400 \mathrm{~g}$ of vegetables and fruits (VF) per day, table 1 . The WHO recommendation has been adopted by the UK and other European authorities (Department of Health, 1994; Scottish Office 1993). This can be achieved by eating a variety of two portions of fruit and three of vegetables per day.

Childhood is a critical period for the development of eating habits which may be carried into adulthood especially VF consumption (Kelder et al., 1994). According to the National Diet and Nutrition Survey for Young People (Gregory et al., 2000) one in five children are not eating fruit in any 1 week.

Teaching children about VF is important as insufficient intake of these foods has been reported as a risk factor for obesity, cancer and stroke in adulthood (Lakkakula et al., 2008). Giving children opportunities to learn more about VF, including their benefits and portion sizes, may help to facilitate increases in their vegetable and fruits intake. Studies have found that school-base nutrition education programs can help increase the consumption of VF. Nutrition education is an effective tool in promoting healthy eating habits (Leupker et al., 1996). Schools can play a big role in shaping children's health behaviour, however, most schools do not provide the recommended 50 hours of instruction needed to achieve behaviour change (Mullen \& Shield, 2004). 
While a number of school-based programs employing various intervention methods have been developed and tested to encourage consumption of VF among children (Tuuri et al., 2009), and the number of recommended daily portions tends to be known to them, there is a gap in their knowledge in regard to what constitutes a portion of VF (Mullarkey et al., 2007; Frobisher \& Maxwell, 2003). In addition, there is an existing confusion as to what counts and doest count as a fruit or vegetable (i.e. blueberry muffins, ketchup, potatoes) (anecdotal evidence). Although children are encouraged by existing public health campaigns to increase their consumption of VF, they are not always familiar with them (Baxter \& Thompson, 2002). As a result, there is a need to investigate a way which is simple, quick and cost effective to clarify existing concept limitations such as what counts towards meeting VF daily intake recommendations.

\section{Materials and methods}

\section{Sample size and recruitment}

Participants, children of grades 3 and 5, were recruited from three primary schools in Leeds UK. As the study was conducted in the framework of the Leeds Science Festival convenience sampling was applied achieving a participation of 80 children. The study was conducted according to the guidelines laid down in the Declaration of Helsinki.

\section{Questionnaire design for initial and final assessment}

A structured questionnaire was developed to test the effect of the intervention. The questionnaire was composed of 8 questions and structured into three sections; I) Section one focused on habitual consumption of VF, II) on snacking and III) three on nutritional knowledge. Closed, multiple choice questions were used to facilitate responding process for the children. The same questionnaire was applied pre and post VFEA.

\section{Intervention}

A structured questionnaire was administered in a classroom setting and divided into two parts. Part I, initial assessment, was applied before the Vegetable and Fruit Education Activity (VFEA) in order to measure the 
children's knowledge and eating habits of VF. Part II, final assessment, was done after the VFEA with the objective of measuring the impact of the intervention.

The VFEA addressed three different complementary aspects of VF portion sizes. Part I focused on what counts as a portion of vegetables, part II on what counts as a portion of fruits and part III, fake friends, considered what does not count as either a portion of vegetable or fruit but might be a source of confusion for the children (i.e. fruit yogurts, blueberry muffins, ketchup). For each part of the VFEA the children were presented with actual food portion samples of vegetables/fruits and were given an oral explanation of how to measure their individual portions. Emphasis was placed on providing the children with comprehensive units of portions in addition to the indicated grams as it was considered important by the researchers that they leave with measurements that are realistically applicable on a daily bases. Hence, children were provided with tablespoon, cup and handful equivalent approximations to the weight of VF portions. Figure 1 illustrates the study design.

\section{Statistical analysis}

Paired sample t-test was performed in order to determine the significance of difference in the increment of knowledge due to the intervention and analysis of variation was used to measure the difference between and across genders before and after the intervention. Differences in snack and restaurant food selection were also explored by this test. Results are presented by age group and gender for comparison.

\section{Results}

\section{Participant characteristics}

Boys and girls of age between 7 and 10 years participated in the study. The children were of various ethnic backgrounds and socio-economical levels although the influence of these factors was not further investigated. The VFEA was carried out in their regular classroom at school and during a normal day timetable. All teachers were present during the activity; 
however, they were discouraged to intervene by helping with the answering of the questionnaire. The children had the option of asking for assistance from the researchers in regard to the clarity of questions. Prompting answers was avoided by the researchers.

\section{Regular consumption of fruits and vegetables}

The majority of participants $(81 \%)$ reported having consumed vegetables the previous day while the number raised even higher $(89 \%)$ when asked about fruit. More girls than boys consumed VF on a regular bases, when compared by paired sample t-test the differences were statistically significant ( $p=.014$ vegetables, $p=0.001$ fruit) (Figure 2). One way ANOVA with Post Hoc Bonferroni multiple comparison analysis was used to observe variation of VF consumption by age group, no significant differences were found (Sig. 0.75-1.00).

\section{Snacking and restaurant food preference}

The preferred snack food for the children was chocolate, followed by carrot sticks and then ice-cream. Following the VFEA preferences changed with carrot sticks leading as the preferred snack. Differences were statistically significant for change in preference of snack foods for all three choices (chocolate and carrot sticks .000 and ice-cream .007). The preferred food consumed at restaurants (away from home) was pizza, followed by fries and salad; after the VFEA salad proved to be the most popular. Changes in preferred restaurant food were significant for salad and pizza (.000 and .002 respectively) but not for fries.

\section{Initial knowledge}

The participants were initially well informed regarding the UK recommendation of 5-a-day portions of fruits and vegetables with $85 \%$ of them being able to report this. Half of the participants were able to recognize the 5 food groups into which food is categorized in the UK. Only $2 \%$ of the participants were able to correctly identify the corresponding portions of apple, juice, grapes, peas and broccoli. 


\section{Acquired knowledge}

Changes in the knowledge between results before and after the VFEA were defined as acquired knowledge. This was measured for VF daily intake recommendations, food groups and portion sizes for foods in the vegetable and fruit groups. Acquired knowledge was statistically significant as shown in Table 3.

\section{Discussion}

The objective of the present study was to evaluate the effectiveness and feasibility of a Vegetable and Fruit Education Activity on primary school children to address the blurred knowledge regarding VF portion sizes. By carrying out a succinct intervention at various schools we were able to detect a significant improvement in portion size knowledge. Improvement of nutritional knowledge of school children by means of classroom-based activities has been reported by various authors (Vijayapushpam et al., 2003; Subba Rao et al., 2006); further, nutritional knowledge has been positively associated with VF intake (Lytle et al., 2003). However, our study was unique in that it addressed specifically the knowledge of portion size and not the importance of VF consumption as has been done in the past.

Instruments used to measure VF intake vary depending on the aim of the research. For this study a closed-question designed was employed as interest was on regular habits and not on nutrient calculation or frequency of consumption. Similar tools have been used in the past with questions such as "...eating fruit and vegetables on previous day (yes/no)" and "type of food eaten for snack" (Baxter and Thompson, 2002; Cullen \& Zakeri, 2004). By employing this method of enquiring consumption habits we were able to detect patterns of VF consumption episodes on a given day bases. Gender differences were observed both for habitual consumption and for knowledge of portion size. More girls than boys reported consuming VF; these results are in accordance to those reported by Rasmussen et al. (2006) 
were more studies tend to report girls as having higher or more frequent intake of fruits and/or vegetables.

Vegetable and fruit consumption tends to decrease with increasing age (Talvia et al., 2006; Kristjansdottir et al., 2010). While we found this to be the case for fruits, where older children had a lower consumption, we did not find a correlation between age and vegetable intake.

The intention of change in regard to VF, influenced by peer pressure, has been studied by Lowe et al. (2004) who found a positive association to actual consumption. In addition, they reported peer-modelling as showing ample increase in expressed liking of VF. Similarly, our results suggest an approximate 50\% likelihood to change dietary habits among the children who participated in the study. In this study the intention to change consumption habits was observed after the participants had gone through the VFEA.

The increase in knowledge of portion sizes that we were able to detect may have a significant impact of VF intake and increase the possibility of reaching the 5-a-day UK recommendations (NHS, 2011).

\section{Strengths and limitations}

The VFEA is a succinct intervention that builds on previous public health awareness campaigns. In addition to having the advantage of not taking up mayor amounts of time assigned to previously planned curricula, the low cost of this intervention as well as its appeal to young children make it an ideal school intervention. By combining visual and oral stimulation as well as active participation from the children, this feasible intervention is both enjoyable and successful at increasing the knowledge of portion sizes of VF.

The main limitation of the study was the reduced sample sizes. However, as variation between results of the different schools was not significant we venture to suggest that similar results would be achieved if the VFEA was applied on a larger scale. Challenges with small sample size are a common phenomenon for this type of research. In a review by 
Rasmussen et al. (2006) it was reported that $81 \%$ of the papers found addressing the determinants of fruit and vegetable consumption among children were not representative due to sample size.

The application of the VFEA methodology proved to be successful in achieving the aim of increasing the knowledge of vegetable and fruit portion sizes among primary school children. A succinct intervention, which can be implemented without disturbance to the established curricula, can be carried out at primary schools in order to increase the knowledge on portion sizes for vegetables and fruits.

\section{Acknowledgments}

The authors are grateful to the schools, teachers and children who willingly participated in the VFEA and to the University of Leeds for the invitation to participate in the Leeds Science Festival, particularly Louise Crabtree for the organization and school liaison.

\section{Sources of funding}

This work was supported by the Leeds Science Festival 2011. The Public Authority for Applied Education and Training in Kuwait provided $\mathrm{PhD}$ sponsorship for $\mathrm{WH}$ and FA. The Mexican National Council of Science and Technology (CONACYT) provided $\mathrm{PhD}$ sponsorship for SDGD.

\section{References}

- Anderson, J.W., Baird, P., Davis, Jr. R.H., Ferreri, S., Knudtson, M., Koraym, A., Waters, V. \& Williams, C.L. (2009) Health benefits of dietary fibre. Nutrition Reviews 67(4), 188-205.

- Baxter, S.D. \& Thompson, W.O. (2002) Fourth grade children's consumption of fruit and vegetable items available as part of school lunches is closely related to preference. J Nutr Educ Behav 34, 166-171.

- Cullen, K.W. \& Zakeri, I. (2004) Fruits, vegetables, milk and sweetened beverages consumption and access to a la carte/snack bar meals at school. Am J Public Health 94(3), 463-467. 
- Department of Health (1994). Nutritional aspects of cardiovascular disease. London: HMSO.

- Frobisher, C. \& Maxwell, S.M. (2003) The estimation of food portion sizes: a comparison between using the pictures of portion and a photographic food atlas by children and adults. J Hum Nutr Diet 16, 181-188.

- Gregory, J., Lowe, S., Bates, C.J., Prentice, A., Jackson, L.V., Smithers, G.,

- Wenlock, R., Farron, M. (2000) National Diet and Nutrition Survey: Young People aged 4-18 Years-Val. 1. Report of the Diet and Nutrition Survey. London: Stationary Office.

- International Agency for Research on Cancer (2003) IARC Handbooks of Cancer Prevention. Volume 8. Fruit and Vegetables. IARC Press: Lyon.

- Kelder, S.H., Perry, C.L., Klepp, K. \& Lytle, L.L. (1994) Longitudinal tracking of adolescent smoking, physical activity, and food choice behaviors. Am J Public Health 84, 1121-1126.

- Kristjansdottir, A.G., Johannsson, E. \& Thorsdottir, I. (2010) Effects of a schoolbased intervention on adherence of 7-9-years-olds to food-based dietary guidelines and intake of nutrients. Public Health Nutrition 13(8), 1151-1161.

- Lakkakula, A.P., Zanovec, M., Silverman, L., Murohy, E. \& Tuuri, G. (2008) Black children with high preferences for fruits and vegetables are at less risk of being at risk of overweight or overweight. J Am Diet Assoc 108, 1912-1915.

- Leupker, R.V., Perry, C.L., McKinlay, S.M., Nader, P.R., Parcel, G.S. \& Stone, E.J. (1996) Outcomes of a field trial to improve children's dietary patterns and physical activity. JAMA 275, 768-776.

- Lowe, C.F., Horne, P.J., Tapper, K., Bwodery, M. \& Egerton, C. (2004) Effects of a peer modelling and rewards-based intervention to increase fruit and vegetable consumption in children. Eur J Clin Nutr 58, 510-522.

- Lytle, L.A., Varnell, S., Murray, D.M., Story, M., Perry, C., Birnbaum, A.S. \& Kubik, M.Y. (2003) Predicting adolescent's intake of fruit and vegetables. J Nutr Educ Behav 35, 170-178.

- Mullarkey, D., Johnson, B. \& Hackett, A. (2007) Portion size selection of fruits and vegetables by 9- to 10-year-old children in Liverpool. J Hum Nutr Diet 20, 459-466.

- Mullen, M.C. \& Shield, J. (2004) Childhood and adolescent overweight: the health professional's guide to identification, treatment and prevention. American Dietetic Association. Chicago, USA. 
- Newby, P.K. (2009) Plant foods and plan-based diets: protective against childhood obesity? Am J Clin Nutr 89(suppl)1572S-87S.

- NHS. National Health Services. Five a Day. Available from: http://www.nhs.uk/LiveWell/5ADAY/Pages/5ADAYhome.aspx. Accessed 30.03.2011.

- Rasmussen, M., Krølner, R., Klepp, K.I., Lytle, L., Brug, J., Bere, E. \& Due, P. (2006) Determinants of fruit and vegetable consumption among children and adolescents: a review of the literature. Part I: quantitative studies. Int J Behav Nutr Phys Act 3(22).

- Robertson, A., Tirado, C., Lobstein, T., Jermini, M., Knai, C., Jensen, J. H., Ferro-Luzzi, A. \& James, W. P. (2004) Food and Health in Europe: a new bases for action. European series, No. 96.WHO regional publication, Copenhagen.

- Scottish Office (1993). The Scottish Diet. Edinburgh: HMSO.

- Subba Rao, G.M., Raghunatha Rao, D., Venkaiah, K., Anil Kumar, D., Rameshwar Sarma, K.V. (2006) Evaluation of the Food and Agriculture Organization's global school based nutrition education initiative, feeding Minds, Fighting Hunger (FMFH), in schools in Hyderabad, India. Public Health Nutrition 9, 991-995.

- Talvia, S., Rasanen, L., Lagstrom, H., Pahkala, K., Viikari, J., Ronnemaa, T., Arffman, M. \& Simell, O. (2006) Longitudinal trends in consumption of vegetables and fruits in Finnish children in an atherosclerosis prevention study (STRIP). Eur J Clin Nutr 60, 172-180.

- Tuuri, G., Zanovec, M., Silverman, L., Geaghan, J., Solmon, M., Holston, D., Guarino, A., Roy, H., \&Murphy, E. (2009) Smart Bodies school wellness program increased children's knowledge of healthy nutrition practices and selfefficacy to consume fruit and vegetables, Appetite 52, 445-451.

- Vijayapushpam, T., Menon, K. K., Rao, D. R., Antony, G.M. (2003) A qualitative assessment of nutrition knowledge levels and dietary intake of schoolchildren in Hyderabad. Public Health Nutrition 6, 683-688.

- World Health Organisation, (1990) Diet, nutrition and the prevention of chronic diseases. Report series 797

\section{Figure legends:}

- Figure 1 Flow diagram of study and outline of participants

- Figure 2 Vegetable and fruit consumption by gender 


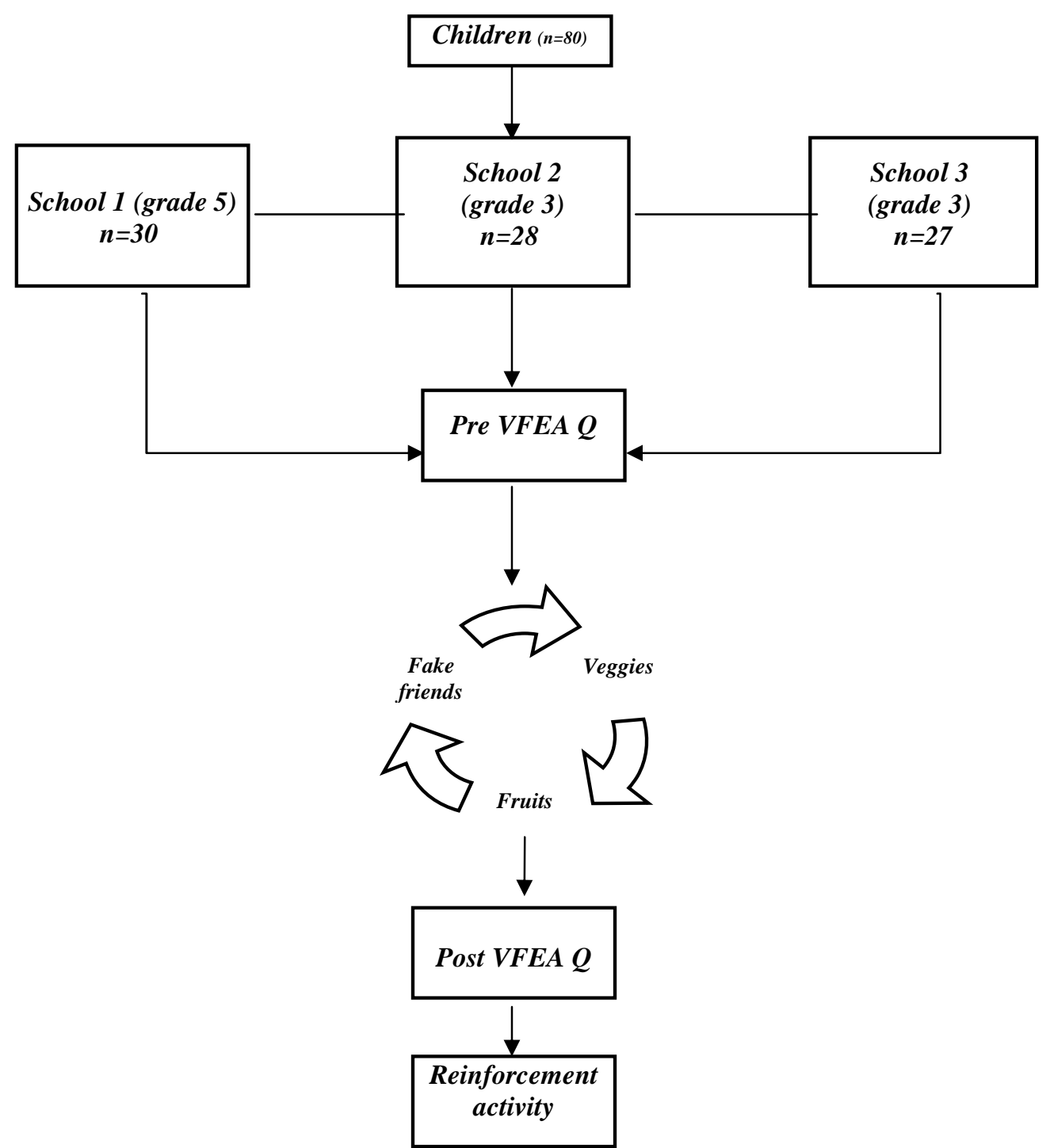

Fig.1 Flow diagram of study and outline of participants 
$=$ Teaching children about nutrition: development of the Vegetable and Fruit Education Activity $=$

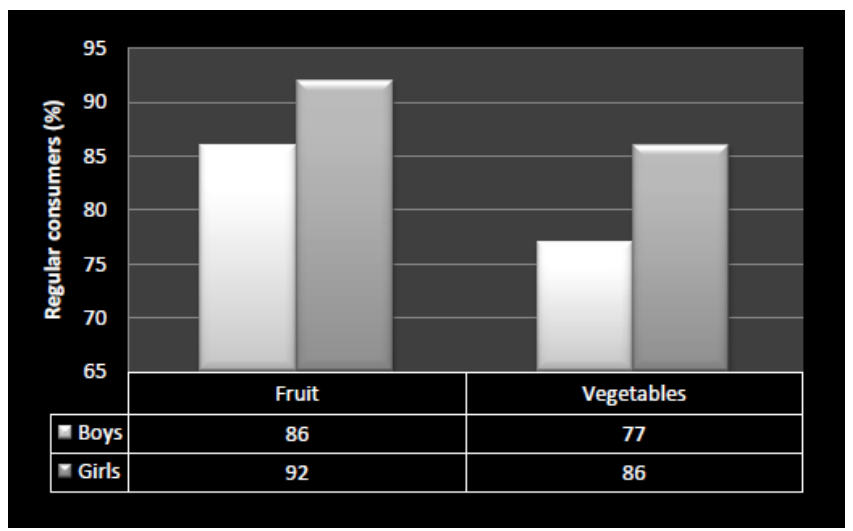

Fig. 2 Vegetable and fruit consumption by gender 


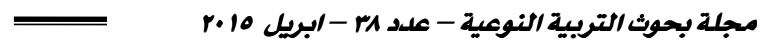

جدول بالعرض 
$=$ Teaching children about nutrition: development of the Vegetable and Fruit Education Activity $=$ 


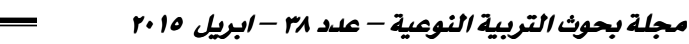

\section{تدريس الأطفال التفذية: تصميم نشاط تعليمي لتدريس الخضراوات والفواكه}

$$
\text { الملخص العربي }
$$

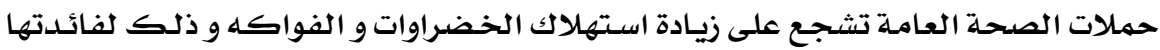

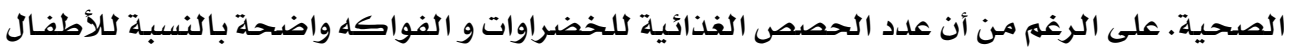

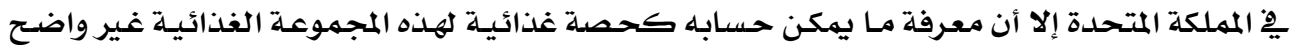
داخل المجتهـع البريطاني.

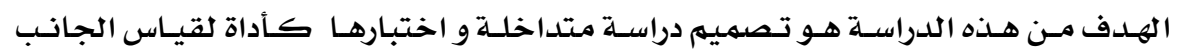

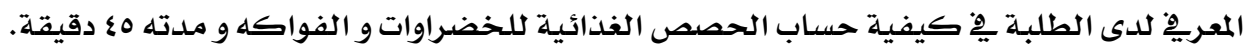

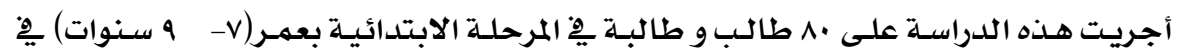

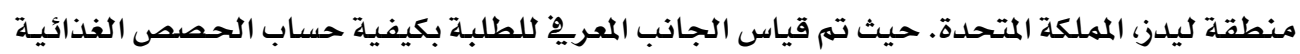

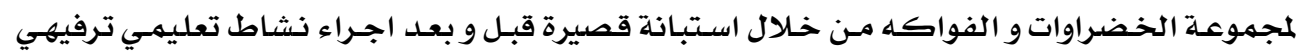
(التعلهم من خلال اللعب) خاص بحملة توعوية من جامعة ليدز، المملكة المتحدة.

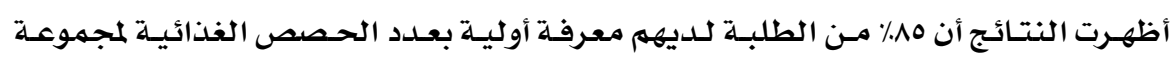

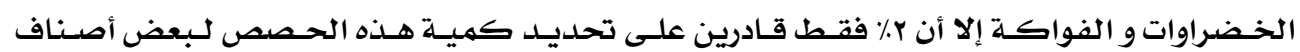

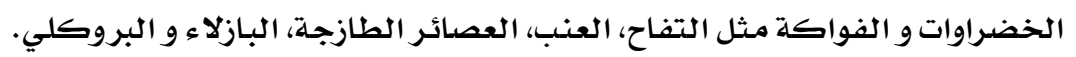

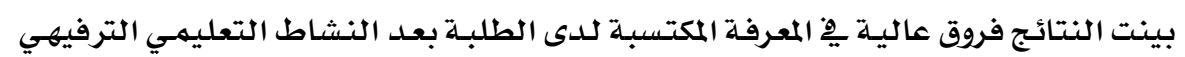

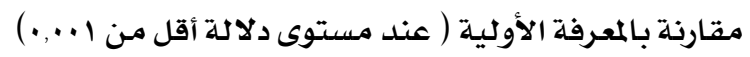

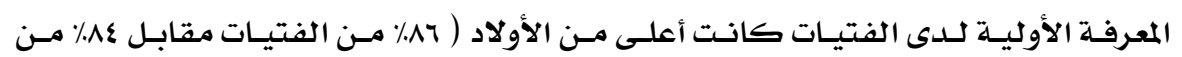

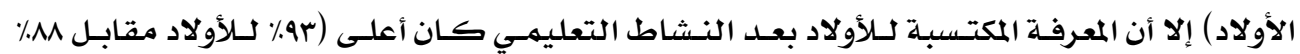

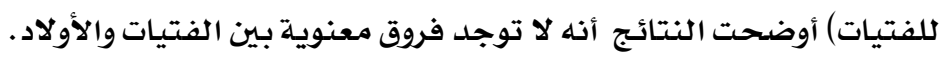

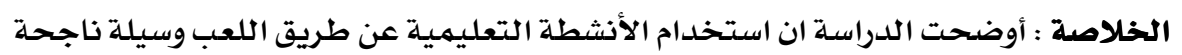

ِِِ زيادة المعرفة لدى الطلبة ِِِ المرحلة الابتدائية.

الكلمات الكاشفة: الحصص الغذائية، العادات الغذائية، تغذية الطفل و المجاميع الغذائية 